\title{
Per- and poly-fluoroalkyl substances (PFASs) in the urban, industrial, and background atmosphere of Northeastern China coast around the Bohai Sea: Occurrence, partitioning, and seasonal variation
}

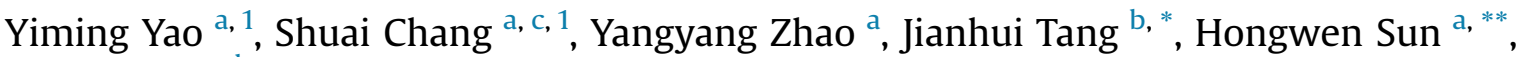 \\ Zhiyong Xie ${ }^{\mathrm{d}}$ \\ a MOE Key Laboratory of Pollution Processes and Environment Criteria, College of Environmental Science and Engineering, Nankai University, Tianjin \\ 300071, PR China \\ ${ }^{\mathrm{b}}$ Key Laboratory of Coastal Environmental Processes \& Ecological Remediation, Yantai Institute of Coastal Zone Research, Chinese Academy of Sciences, \\ Yantai 264003, Shandong, PR China \\ ${ }^{\mathrm{c}}$ Beijing Orient Electronics Technology Group, Beijing 100176, PR China \\ ${ }^{\mathrm{d}}$ Helmholtz-Zentrum Geesthacht, Centre for Materials and Coastal Research GmbH, Institute of Coastal Research, 21502 Geesthacht, Germany
}

\section{H I G H L I G H T S}

- Both neutral and ionic PFASs can be transported to an isolated island via atmosphere.

- Particulate matter is an important carrier of PFASs during atmospheric transport.

- Ionic PFASs were found at substantial levels both in gas and particle phases.

- The temperature-dependent partitioning of FTOHs to particles was significant in winter.

- DiPAPs were detected only in particle phase with a low level range of 0.02 $-6.72 \mathrm{pg} \mathrm{m}^{-3}$.

\section{A R T I C L E I N F O}

\section{Article history:}

Received 26 March 2017

Received in revised form

21 July 2017

Accepted 8 August 2017

Available online 10 August 2017

\section{Keywords:}

PFASs

Occurrence

Partitioning

Seasonal variation

Atmospheric transport

China
G R A P H I C A L A B S T R A C T

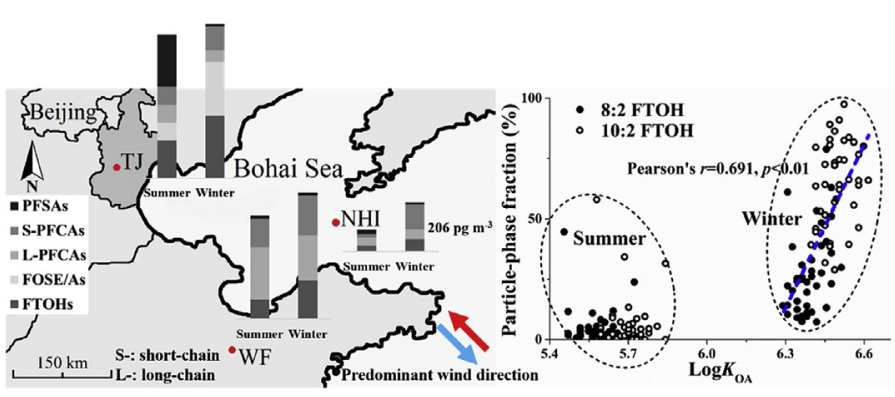

\footnotetext{
* Corresponding author.

** Corresponding author.

E-mail addresses: jhtang@yic.ac.cn (J. Tang), sunhongwen@nankai.edu.cn (H. Sun).

1 Co-first authors.
} 
particle phases and particulate matter was important for atmospheric transport and for determining the fate of PFASs, especially in areas close to a source region.

(C) 2017 Elsevier Ltd. All rights reserved.

\section{Introduction}

Per- and poly-fluoroalkyl substances (PFASs) are a class of synthetic chemicals that have been widely used in a variety of industrial and commercial products, including textile coating, leather and paper treatment, pesticide, and fire-fighting foams, due to their unique properties such as surface activity and chemical stability (Kissa, 2001; Buck et al., 2011). Perfluoroalkyl acids (PFAAs), including perfluoroalkyl carboxylic acids (PFCAs) and perfluoroalkane sulfonic acids (PFSAs), which are directly released or formed from PFAS precursors (Wang et al., 2014c), have been detected globally in all kinds of environmental matrices (Dreyer et al., 2009b; Zhao et al., 2012; Wang et al., 2015b; Lam et al., 2016). Perfluorooctanoic acid (PFOA) and perfluorooctane sulfonic acid (PFOS) are legacy long-chain PFAAs and have been phased out in most developed countries (3M, 2000; US-EPA, 2010), due to their ubiquitous occurrence, environmental persistence, bioaccumulative, and toxic effects on wildlife and human beings (Lau et al., 2007; Wang et al., 2014b; Gao et al., 2015). Meanwhile, production of long-chain PFAAs and their precursor fluorotelomer alcohols (FTOHs) has been rehabilitated and has prospered in Asian countries, especially in mainland China (Wang et al., 2014c). The still active production as well as huge consumption of PFAS-based products due to dense population and high economic development speed has made the core developing districts around the Bohai Sea a source region of PFASs.

Neutral PFASs, such as FTOHs and perfluorooctane sulfoamidoethanols/sulfonamides (FOSE/As), are volatile precursors with relatively long atmospheric lifetimes of 20-50 days (Ellis et al., 2003; Piekarz et al., 2007), and can be photo-transformed into PFAAs. Hence, their long-range atmospheric transport (LRAT) and subsequent degradation are recognized as a source of PFAAs in remote regions (Stock et al., 2007; Benskin et al., 2011). PFAAs are nonvolatile substances with high water solubility (Vierke et al., 2013); thus, not as much effort as to their precursors has been made to clarify their occurrence and behavior in the atmosphere. However, high levels of these ionic PFASs have been found in precipitation globally close to source regions (Kwok et al., 2010; Zhao et al., 2013), suggesting that ionic PFASs may also occur in the atmosphere. Till now, very few studies have investigated the levels of ionic PFASs in the atmosphere. Ionic PFASs have been reported in the particle phase in the atmosphere of Zürich, Switzerland, and the concentrations were generally below $10 \mathrm{pg} \mathrm{m}^{-3}$. In contrast, the total concentrations of ionic PFASs in the atmosphere of Tianjin, China exceeded $100 \mathrm{pg} \mathrm{m}^{-3}$, comparable to those of FTOHs (Yao et al., 2016a). High particle-phase levels of ionic PFASs have also been reported in the atmosphere of Northwest Europe at 25-574 pg m ${ }^{-3}$ (Barber et al., 2007). Hence, more field data are needed to clarify not only the occurrence of PFASs in the atmosphere but also the phase distribution and potential for atmospheric transport.

Partitioning between gas and particle phases is an important process that affects the fate of a chemical in the atmosphere. A limited number of field studies have reported the occurrence of neutral PFASs in the particle phase of the atmosphere and their levels were consistently low (Dreyer et al., 2009b; Cai et al., 2012; Müller et al., 2012; Wang et al., 2014d). Nevertheless, FTOHs were able to partition effectively to both organic and mineral surfaces of particulate matter (Arp et al., 2006; Li et al., 2006; Thuens et al., 2008). FOSE/As were shown to be able to enrich in the finest particles (Dreyer et al., 2014). A ubiquitous occurrence of both neutral and ionic PFASs in the outdoor dust on a continental scale and an association with possible atmospheric transport have been reported (Yao et al., 2016b). Partitioning to particles and their subsequent deposition were suggested as a major loss mechanism during the atmospheric transport of neutral PFASs from a source region to the open ocean (Lai et al., 2016). This process may be influenced by the level of total suspended particles (TSP) (Wang et al., 2015a; Yuan et al., 2016), and more field evidence is needed to clarify partitioning behaviors, especially in a source region with high TSP levels.

Polyfluoroalkyl phosphoric acid diesters (diPAPs) are FTOHbased substances that have been widely used in food packaging for surface treatment and as additives in pesticides and personal care products (Buck et al., 2011; Lee and Mabury, 2011). DiPAPs have a relatively long history of use but came into scientific view only in recent years (D'eon et al., 2009; Lee and Mabury, 2011; Yeung et al., 2013). Much higher levels of diPAPs have been measured in indoor dust and human serum, where 6:2 and 8:2 diPAPs were dominant homologues (De Silva et al., 2012). However, reports on diPAPs in the outdoor environment especially in the atmosphere are still limited (Loi et al., 2013; Kwok et al., 2015; Yao et al., 2016b).

Hence, the goals of this study were to determine the occurrence, phase distribution, and seasonal variation therein of a suite of neutral and ionic PFASs, including diPAPs, at an urban site, an industrial site, and an oceanic island (background site) in a source region around the Bohai Sea, China. The gas- and particle-phase samples were collected simultaneously from August to September 2014 (summer) and from December 2014 to January 2015 (winter) with high-volume active air samplers (HV-AASs). Data presented in this study yield new information on spatial and temporal variations of PFASs in the atmosphere and their gas/particle partitioning behaviors. The results of this study also allow the identification of ionic PFASs and diPAPs of emerging concern in the atmosphere, on which the information is relatively scarce.

\section{Materials and methods}

\subsection{Chemicals and standards}

The target analytes included 6:2, 8:2, and 10:2 FTOHs; $N$-methyl and $N$-ethyl FOSAs ( $N$-MeFOSA and $N$-EtFOSA); $N$-methyl and $N$ ethyl FOSEs ( $N$-MeFOSE and $N$-EtFOSE); PFCAs with carbon chain lengths of 4-12 (PFBA, PFPeA, PFHxA, PFHpA, PFOA, PFNA, PFDA, PFUnDA, and PFDoDA, respectively); PFSAs with carbon chain lengths of 4,6 , and 8 (PFBS, PFHxS, and PFOS, respectively); 6:2 and 8:2 fluorotelomer unsaturated carboxylic acids (FTUCAs); and 6:2 and 8:2 diPAPs. Eleven internal standards (M5-6:2 FTOH, M4-8:2 FTOH, M5- $N$-EtFOSA, M9- $N$-EtFOSE, M4-PFOA, M4-PFBA, M4PFOS, M4-PFHXS, M2-8:2 FTUCA, M4-8:2 diPAP, and M4-6:2 diPAP) were used in quantification. All the standards are of $>97 \%$ purity. Amberlite XAD-2 resin ( $35 \mathrm{~g}$, particle size $0.3-1.0 \mathrm{~mm}$ ) was obtained from Supelco (Sigma-Aldrich, PA, USA). Polyurethane 
foam (PUF) slices $(3 \times 2.5$ in) were purchased from Tisch Environmental (OH, USA) and glass fiber filters (GFFs, pore size: $0.7 \mu \mathrm{m}$ ) from the Whatman Company (GE, USA). All solvents (acetone, dichloromethane, methanol, and n-hexane) were of residue grade and re-distilled in a full glass system prior to use. Details of standards information and the use of internal standards are given in Table S1 in the supporting information (SI).

\subsection{Sampling campaign}

The sampling campaign was conducted from August to September 2014 and from December 2014 to January 2015 at three sampling sites around the Bohai Sea, Northern China: Tianjin (TJ), Weifang (WF), and North Huangcheng Island (NHI). All sites were carefully selected to avoid high trees or buildings to ensure good air circulation. Tianjin is one of the largest industrial and harbor cities in Northern China with a population of 17 million. It is located on the west coast of the Bohai Sea. Air samples were taken on the rooftop of a four-story building on the campus of Nankai University in the central city, which has a dense population and heavy commercial activities. Weifang is an important industrial city of the Shandong province. Air samples were taken on the rooftop of a seven-story residential building. There is a suite of industrial activities around the WF sampling site, such as the chlor-alkali industry, brominated flame retardant manufacturing, a paper mill, and pesticides production. Extremely high levels of PFOA were detected in the nearby Xiaoqing River (Heydebreck et al., 2015), implying the presence of potential emission sources of PFASs in the vicinity. NHI is located in the middle of Bohai Strait and is approximately $60 \mathrm{~km}$ off the continent to the south and $40 \mathrm{~km}$ to the north. The island has an area of about $2.7 \mathrm{~km}^{2}$ and a population of 2 400. Marine aquaculture and fishing are the main income source and the island is self-sustaining with no other industry activity. The HV-AAS was located on a platform approximately $20 \mathrm{~m}$ above the sea level on a hilltop. It is at the eastern cape of the island and faces the sea to the north, east, and south. The sampling map is shown in Fig. S1.

Air samples were collected using HV-AAS (GKSS, Germany) over a 24 -h period with sample volumes of approximately $300 \mathrm{~m}^{3}$. The sampling period at each site lasted for about one month with filters replaced daily. Attempts were made to sample at all three locations simultaneously. Half the samples (15 in summer and 14 in winter) from every alternative day were used in this study. Details of high volume air samplers are described elsewhere (Shoeib et al., 2006; Wang et al., 2014d). Briefly, the sampling train comprised a GFF (90 mm diameter) to screen airborne particles and a self-packed PUF-XAD sandwich to trap gas-phase compounds. The cartridge consisted of $35 \mathrm{~g}$ XAD-2 resin topped with one PUF plugs $(5.0 \mathrm{~cm}$ in diameter and $2.5 \mathrm{~cm}$ in thickness). Fluoropolymer materials were not used in the high-volume air sampler to avoid possible contamination of the target compounds. After sampling, the filters were stored at $-20{ }^{\circ} \mathrm{C}$ and the air cartridges were stored at $4{ }^{\circ} \mathrm{C}$ until analysis in the laboratory. All samples were extracted within two months from collection. Detailed information on the sampling sites, sampling dates, air volume, temperature, wind speeds during the sampling period, and other parameters can be found in Tables S2-7 in the SI.

\subsection{Sample preparation and instrumental analysis}

Air sample media (PUF/XAD and GFFs) were extracted with modified Soxhlet apparatus. Air columns (PUF/XAD cartridge) and GFFs were spiked with $5 \mathrm{ng}$ of each internal standard mentioned above before extraction. Air columns were extracted with dichloromethane for $24 \mathrm{~h}$ for all PFASs and successively with methanol for another $24 \mathrm{~h}$ for possible residual ionic PFASs and PAPs. For filter samples, the filter was cut in half. Half was used for Soxhlet extraction with dichloromethane for $24 \mathrm{~h}$ to recover neutral PFASs and the other half was ultrasonically extracted for three times with $5 \mathrm{~mL}$ methanol each time for ionic PFASs and PAPs. The three extracts were combined. All extracts from the Soxhlet extraction were concentrated with rotary evaporation to approximately $2 \mathrm{~mL}$. The extracts of dichloromethane were exchanged to n-hexane and were passed through a column of $3 \mathrm{~g} \mathrm{Na}_{2} \mathrm{SO}_{4}$ to remove residual water and further concentrated to about $0.5 \mathrm{~mL}$ under a gentle stream of high purity nitrogen. The extracts of methanol were cleaned with dispersive Envi-carb. Especially for the extraction of air columns, an aliquot of n-hexane solution was directly used for analysis of neutral PFASs while another aliquot of n-hexane was evaporated to dryness and re-dissolved with an equal aliquot of the subsequent extract of methanol, the combination of which was used for analysis of ionic PFASs and diPAPs. Breakthrough of the sampling method was checked randomly using two columns connected in series (Xie et al., 2013). The recoveries of PFASs were all above $90 \%$, indicating a good retention of the target analytes.

Analysis for FTOHs and FOSE/As were performed using an Agilent 7890 gas chromatography coupled with an Agilent 5975C mass spectrometer in selective ion monitoring (SIM) mode with positive chemical ionization ( $\mathrm{PCI}$ ) using methane as reagent gas. The analytes were separated on a $30 \mathrm{~m}$ DB-WAX column (30 $\mathrm{m} \times 0.25 \mathrm{~mm} \times 0.25 \mu \mathrm{m})$. Helium was used as the carrier gas at a flow rate of $1.3 \mathrm{~mL} \mathrm{~min}^{-1}$ and the injection volume was $3.0 \mu \mathrm{L}$ in the pulse splitless mode.

Analysis of ionic PFASs was performed with a high-performance liquid chromatograph-tandem mass spectrometer (HPLC-MS/MS). The instrument was an Agilent 1200 series liquid chromatograph interfaced with an Agilent G6410B triple quadrupole mass spectrometer (Agilent Technologies, USA) and operated in the electrospray negative ionization multiple-reaction monitoring (MRM) mode. Nitrogen with a purity of $99.9 \%$ was used as desolvation gas at a flow rate of $10 \mathrm{~L} \mathrm{~min}^{-1}$ and a manipulating temperature of $350{ }^{\circ} \mathrm{C}$. The nebulizer gas pressure was $50 \mathrm{psi}$. The capillary voltage was $4 \mathrm{kV}$. The dwell time was $200 \mathrm{~ms}$.

The X-terra MS C18 column (2.1 mm i. D. $\times 150 \mathrm{~mm}, 5 \mu \mathrm{m}$, Waters, Ireland) was used for the separation of ionic PFASs. A $10-\mu \mathrm{L}$ aliquot of the extract was injected. A gradient operation was optimized as $6 \%$ methanol, increased uniformly to $58 \%$ at $0.8 \mathrm{~min}$, to $100 \%$ at $12.8 \mathrm{~min}$, reversed to original conditions at $14.3 \mathrm{~min}$, and held until $26 \mathrm{~min}$ when the equilibrium was reached. The mobile phase flow rate was $250 \mu \mathrm{L} \mathrm{min}{ }^{-1}$. Both mobile phases contained $2.5 \mathrm{mM}$ ammonium acetate. Especially for the separation of diPAPs, methanol and alkaline Milli-Q water $(\mathrm{pH}=10)$ were used as the mobile phases, with a gradient operation where $20 \%$ methanol was increased uniformly to $80 \%$ at $2 \mathrm{~min}$ and held for $1 \mathrm{~min}$, increased uniformly to $95 \%$ at $6 \mathrm{~min}$, held for $5 \mathrm{~min}$, and reversed to original conditions at $12 \mathrm{~min}$ until the equilibrium was reached at $22 \mathrm{~min}$. The flow rate was kept at $300 \mu \mathrm{L} \mathrm{min}{ }^{-1}$. The injection volume was $10 \mu \mathrm{L}$.

Details regarding the instrumental analyses are provided in Table S8 in the SI.

\subsection{Quality assurance and quality control}

All air columns were pre-cleaned with organic solvents (methanol, acetone, dichloro-methane, and n-hexane in series, and each for $24 \mathrm{~h}$ ) and GFFs were baked at $450{ }^{\circ} \mathrm{C}$ for $12 \mathrm{~h}$ prior to use. $\mathrm{Na}_{2} \mathrm{SO}_{4}$ was cleaned with dichloromethane for $12 \mathrm{~h}$ and baked at $450{ }^{\circ} \mathrm{C}$ for $12 \mathrm{~h}$ prior to use. The air columns were wrapped in aluminum foil before and after sampling. Deionized water with a 
resistivity of $18 \mathrm{M} \Omega-\mathrm{cm}$ was used throughout the study. Laboratory ware was rinsed carefully with methanol before use. Field blanks (clean air columns and GFFs) were taken to each sampling site, exposed shortly (approximately $1 \mathrm{~min}$ ) to ambient air, and brought to the laboratory together with the environmental samples for extraction and analysis. Some analytes were detected in these field blanks, showing low values with concentrations in final solvent samples ranging from 0.08 to $0.33 \mathrm{ng} \mathrm{mL}^{-1}$ (Table S8). Limit of detection (LOD) was derived from the peak value with the signalto-noise ratio (SNR) equaling three and limit of quantification (LOQ) was from the peak value with SNR equaling ten. Method detection limits (MDLs) for analytes detected in the field blanks were derived from three times the standard deviation of field blank values and the concentrations were subtracted from mean blank values. For analytes not detected or below the LOQs in the field blanks, three times the LODs were calculated as MDLs instead. The MDL values for each analyte are given in Table S8. In addition, recovery standards were added to each of the samples to monitor procedural performance. Average recoveries for the analytes in air columns was between $42 \pm 16 \%\left({ }^{13} \mathrm{C}-6: 2 \mathrm{FTOH}\right)$ and $125 \pm 14 \%\left({ }^{13} \mathrm{C}-\right.$ $\mathrm{N}$-EtFOSE). Average recoveries for the analytes in filters were between $73 \pm 14 \%\left({ }^{13} \mathrm{C}-\mathrm{PFDA}\right)$ and $113 \pm 19 \%\left({ }^{13} \mathrm{C}\right.$-PFOA $)$. The low recoveries for ${ }^{13} \mathrm{C}-6: 2 \mathrm{FTOH}$ are associated with the high volatility of this compound and the resulting evaporative losses during Soxhlet extraction and subsequent concentration. Signal enhancement caused by solvent or interfering compounds might be responsible for the high recoveries of ${ }^{13} \mathrm{C}$-PFOA.

\subsection{Air mass backward-trajectories and statistical analysis}

The source regions of the air masses sampled on North Huangcheng Island (NHI) were determined using the NOAA's HYSPLIT model. Air mass backward-trajectories were calculated in 48-h/24-h steps, tracing back the air masses for each sampling endpoint using $10 \mathrm{~m}$ as the arrival height. The results are shown as frequencies of trajectories on a grid resolution of $0.25 \times 0.25^{\circ}$. The details are given in Fig. S2 in the SI. Median values were calculated based on values of detection. Spearman correlation analysis and Mann-Whitney rank analysis were performed with IBM SPSS Statistics 20. All data were logarithmic transformed before correlation analysis and outliers beyond the value of three times the standard deviation plus mean value were not used. All the plots were created with OriginLab OriginPro 8.5.

\section{Results and discussion}

\subsection{Concentration and composition profiles of PFASs in the atmosphere}

FTOHs were dominant neutral PFASs at all three sampling sites. The total air concentrations of FTOHs were the highest at the urban TJ (median: $152-246 \mathrm{pg} \mathrm{m}^{-3}$ ) and the lowest at the background NHI (median: $25.2-54.5 \mathrm{pg} \mathrm{m}^{-3}$ ), and consistently higher in winter than in summer (Fig. 1A and B). 8:2 FTOH was dominant, followed by 10:2 and 6:2 FTOHs. This trend was similar between sites and seasons, which suggested common sources. Particularly at the urban TJ, $N$-EtFOSA was detected with median levels of $69.2 \mathrm{pg} \mathrm{m}^{-3}$ and $215 \mathrm{pg} \mathrm{m}^{-3}$ in summer and winter, respectively, which were 3-4 orders of magnitudes higher than those at WF and NHI.

Ionic PFASs were frequently detected in the atmosphere, with the highest total concentrations at the industrial WF (median 332-348 $\mathrm{pg} \mathrm{m}^{-3}$ ) and the lowest at the background NHI (median $68.7-151 \mathrm{pg} \mathrm{m}^{-3}$ ). At the industrial WF, PFOA was detected at high levels of $16.0-3.85 \times 10^{3} \mathrm{pg} \mathrm{m}^{-3}$ in summer and $38.9-1.56 \times 10^{3} \mathrm{pg} \mathrm{m}^{-3}$ in winter (Fig. 1C). The abundance of PFOA in the atmosphere may account for its previously reported high levels in local rainfalls (Zhao et al., 2013) and in the surface waters of WF City (Yao et al., 2014). Due to more than a decade of development of local fluoropolymer industries, where PFOA has been produced and used as emulsifiers for producing fluoropolymers and fluoroelastomers (Wang et al., 2014a), extremely high levels of PFOA have been measured in local river catchments (up to hundreds of $\mu \mathrm{g} \mathrm{L}^{-1}$ ) and in the estuaries (up to thousands ng $\mathrm{L}^{-1}$ ) (Heydebreck et al., 2015; Wang et al., 2016). This indicates that a direct release of PFOA from these point sources to the atmosphere is significant, in addition to the source of precursors degradation. The median levels of PFOS were $123 \mathrm{pg} \mathrm{m}^{-3}, 11.2 \mathrm{pg} \mathrm{m}^{-3}$, and $18.3 \mathrm{pg} \mathrm{m}^{-3}$ in summer and $10.3 \mathrm{pg} \mathrm{m}^{-3}, 11.0 \mathrm{pg} \mathrm{m}^{-3}$, and $8.84 \mathrm{pg} \mathrm{m}^{-3}$ in winter at TJ, WF, and NHI, respectively. All levels of PFOS were significantly lower than those of PFOA $(p<0.01)$, except in summer when PFOS was particularly detected with high levels (up to $3.83 \times 10^{3} \mathrm{pg} \mathrm{m}^{-3}$ ) at the urban TJ, where $N$-EtFOSA, a direct precursor compound, was also found at high levels (Fig. 1A and C). The variation between seasons (Fig. $1 \mathrm{~B}$ and $\mathrm{D}$ ) suggested an enhanced transformation of FOSE/As to PFOS in summer (D'Eon et al., 2006).

The profiles of short-chain PFASs showed site-specific characteristics and seasonal differences (Fig. 1C and D). In summer, PFHxA and PFBS were frequently detected at TJ with median levels of $47.3 \mathrm{pg} \mathrm{m}^{-3}$ and $57.0 \mathrm{pg} \mathrm{m}^{-3}$, respectively, which were comparable to that of PFOA (58.6 $\mathrm{pg} \mathrm{m}^{-3}$ ), whereas PFPeA and PFBA were detected only occasionally ( $<30 \%)$; at WF, C4-C6 PFCAs were all detected with similar air concentrations of $37.5-42.5 \mathrm{pg} \mathrm{m}^{-3}$ but without occurrence of PFBS. At NHI, no short-chain PFASs were detected with frequencies $>50 \%$ and PFOA was dominant (31.0 $\mathrm{pg} \mathrm{m}^{-3}$ ). In winter, PFBA occurred at dominant levels of $97.1 \mathrm{pg} \mathrm{m}^{-3}, 156 \mathrm{pg} \mathrm{m}^{-3}$, and $98 \mathrm{pg} \mathrm{m}^{-3}$, corresponding to a contribution of $60 \%, 45 \%$, and $65 \%$ at TJ, WF, and $\mathrm{NHI}$, respectively (Fig. 1D); for other short-chain PFASs, only PFHxA was detected frequently at levels of $2.79-12.1 \mathrm{pg} \mathrm{m}^{-3}$, which was much lower than those in summer. These results suggest additional sources for PFBA in the atmosphere, which produce a different seasonal variation from other PFAAs. Levels of PFBA was reported as $0.15-1.5 \mathrm{ng} /$ $\mathrm{L}$ in the open water of the Bohai Sea collected in 2012, which was much lower than those of PFOA (2.3-106 ng/L) (Zhao et al., 2017). This likely atmospheric transport of PFBA or its precursors to the background island was more significant than its oceanic transport. PFBA was detected as a dominant PFCA ( $>50 \%$ ) in Antarctica snow with concentrations up to $0.5 \mathrm{ng} / \mathrm{L}$, while their levels in seawater were less significant (Casal et al., 2017). These results further emphasize the occurrence and transport of PFBA and its precursors in the atmosphere and indicate that the sources of short-chain PFASs are yet to be explained completely.

FTUCAs are important intermediates of heterogeneous degradation of FTOHs (Styler et al., 2013). 8:2 FTUCA was detected in the atmosphere with total air concentrations of $1.01-9.42 \mathrm{pg} \mathrm{m}^{-3}$, $0.93-5.69 \mathrm{pg} \mathrm{m}^{-3}$, and $0.66-2.54 \mathrm{pg} \mathrm{m}^{-3}$. at $\mathrm{TJ}, \mathrm{WF}$, and $\mathrm{NHI}$, respectively, which were not significantly different between seasons $(p>0.05)$. 6:2 FTUCA was seldom detected in winter but at similar levels to 8:2 FTUCA in summer, when PFHxA was measured at high levels. This indicates an enhanced transformation of precursors in the atmosphere in summer. Meanwhile, diPAPs, with relatively high $\log K_{\mathrm{OA}}$ values (12-14) (Wang et al., 2013), were detected only in the particle phase, with total concentrations of $0.07-6.72 \mathrm{pg} \mathrm{m}^{-3}, 0.05-0.38 \mathrm{pg} \mathrm{m}^{-3}$, and $0.02-0.47 \mathrm{pg} \mathrm{m}^{-3}$ at TJ, $\mathrm{WF}$, and NHI, respectively, which were not significantly different between seasons $(p>0.05)$. The levels at TJ were significantly higher than those at WF and NHI in both seasons $(p<0.01)$. 6:2 diPAP was consistently dominant between seasons, while 8:2 diPAP was detected primarily in winter. The differences in atmospheric 

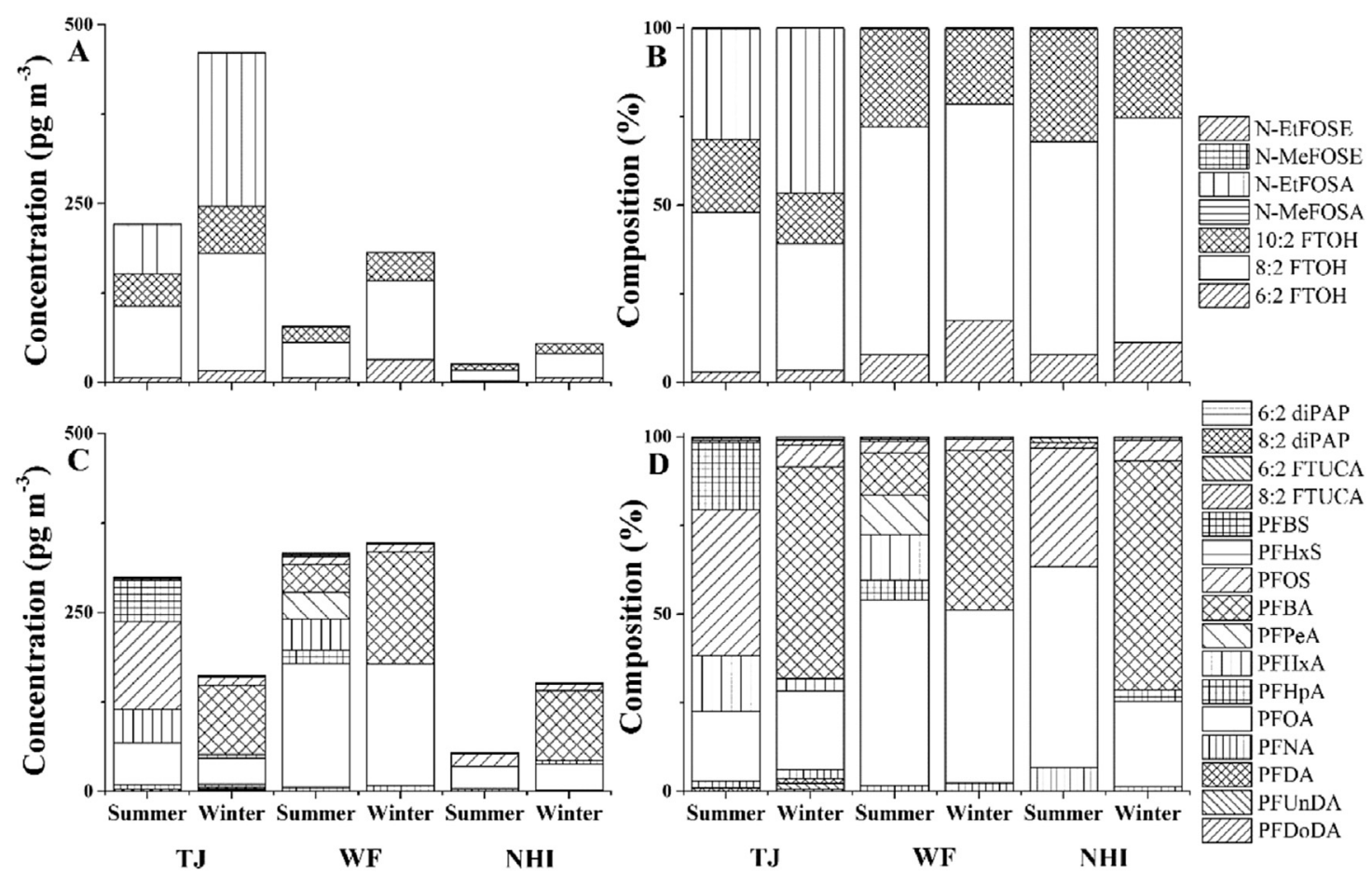

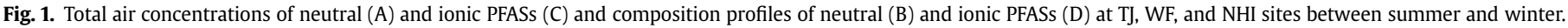
Median value of each PFAS was used and only those with detection frequencies $>50 \%$ are displayed.

levels further demonstrate that urban activities are major sources of diPAPs and their atmospheric transport is associated with particulate matter, which was previously indicated in investigations on outdoor dust (Yao et al., 2016b). The specific concentrations of individual PFAS are shown in Tables S9-12 in the SI.

\subsection{Comparison with literature}

A comparison was made between the data in this study and those in the literature (Table 1). The median levels of FTOHs $\left(151-248 \mathrm{pg} \mathrm{m}^{-3}\right)$ at TJ were higher than mean values from Toronto, Canada (81 $\mathrm{pg} \mathrm{m}^{-3}$ ) (Ahrens et al., 2012); Büsum, Germany (37 $\mathrm{pg} \mathrm{m}^{-3}$ ) (Wang et al., 2014d), and most studies (based on reconverted data) across Japan, India, and other places in China using passive samplers (28.0-78.5 $\mathrm{pg} \mathrm{m}^{-3}$ ) (Li et al., 2011), but lower than those from Zürich, Switzerland $\left(868 \mathrm{pg} \mathrm{m}^{-3}\right.$ ) (Müller et al., 2012) and Manchester, UK (381-527 $\mathrm{pg} \mathrm{m}^{-3}$ ) (Barber et al., 2007). The levels of FTOHs matched those from previous investigation using passive samplers in summer at $\mathrm{TJ}\left(117 \mathrm{pg} \mathrm{m}^{-3}\right.$ ) (Yao et al., 2016a), while much higher levels of FOSE/As were reported in this study. The extremely high levels of FOSE/As at TJ, especially in winter, exceeded most levels in other studies. This could be a site-specific scenario, because $96 \%$ of FOSE/As was particleassociated and the range of influence should be limited. In terms of the oceanic atmosphere, the median levels of FTOHs at NHI (22.0-48.6 $\mathrm{pg} \mathrm{m}^{-3}$ ) were generally higher than those from the Atlantic Ocean (19.9 $\mathrm{pg} \mathrm{m}^{-3}$ ) (Wang et al., 2015b), Station Nord, Greenland (9.34 $\mathrm{pg} \mathrm{m}^{-3}$ ) (Bossi et al., 2016), and Ny-Ålesund, Norway (14 $\mathrm{pg} \mathrm{m}^{-3}$ ) (Xie et al., 2015); they are comparable to those close to source regions such as the North Sea $\left(77.0 \mathrm{pg} \mathrm{m}^{-3}\right.$ ) (Xie et al., 2013) and the South China Sea $\left(53.0 \mathrm{pg} \mathrm{m}^{-3}\right.$ ) (Lai et al., 2016), and lower than those from mobile cruise sampling in the Bohai Sea (104 pg $\mathrm{m}^{-3}$ ), North and South Yellow Seas (184-288 pg m${ }^{-3}$ ) (Zhao et al., 2017), and the Japan Sea (178 $\mathrm{pg} \mathrm{m}^{-3}$ ) (Cai et al., 2012). In addition, the levels of neutral
PFASs at NHI were slightly lower than the samples from the landbased background site of Jixian, Tianjin, but they shared a similar composition profile, suggesting common sources (Yao et al., 2016a).

The median total concentrations of PFCAs in the atmosphere at TJ were $151 \mathrm{pg} \mathrm{m}^{-3}$, which were comparable with results that have been reported previously (Yao et al., 2016a), whereas PFSAs total concentrations in summer were found to be much higher than before (median $209 \mathrm{pg} \mathrm{m}^{-3}$ ), corresponding to the particularly high levels of FOSE/As at the same site. In general, the total air concentrations of ionic PFASs in this study at Bohai Bay are at a much higher level than those at Zürich, Switzerland (mean $38.1 \mathrm{pg} \mathrm{m}^{-3}$ ) (Müller et al., 2012), Toronto, Canada $\left(<10 \mathrm{pg} \mathrm{m}^{-3}\right.$ ) (Ahrens et al., 2013), Manchester, United Kingdom (mean 25.1 pg m$^{-3}$ ) (Barber et al., 2007), or the southeastern region of China (median $12 \mathrm{pg} \mathrm{m}^{-3}$ ) (Liu et al., 2015). It is also expected that the levels of ionic PFASs at $\mathrm{NHI}$ (median $61.7 \mathrm{pg} \mathrm{m}^{-3}$ ) were generally higher than those in coastal areas of Canada $\left(<1 \mathrm{pg} \mathrm{m}^{-3}\right)$ (Gewurtz et al., 2013) and Germany (5.7 $\mathrm{pg} \mathrm{m}^{-3}$ ) (Dreyer and Ebinghaus, 2009). It is noteworthy that most of the studies discussed above used HV-AASs and only accounted for particle-phase ionic PFASs adsorbed on GFFs. The exclusion of ionic PFASs in air PUF columns may lead to an underestimation on their bulk-air levels. Therefore, if HV-AASs are used, it is necessary to analyze ionic PFASs in both phases in order to make the results more comparable (Ahrens et al., 2013; Johansson et al., 2017).

\subsection{Back-trajectory analysis of NHI island data}

The geographic features and self-sustaining nature of NHI mean that the island should be less disturbed and receive contaminants only via atmospheric and oceanic transport. Special care was taken with the air samples detected with the highest total PFAS concentrations. In summer, the highest levels were detected at 222-371 $\mathrm{pg} \mathrm{m}^{-3}$ and long-chain PFCAs were dominant analogues (68\%). As shown in Fig. S2, the air mass trajectories showed high 
Table 1

Summary of FTOHs and FOSE/As air concentrations (gas- and particle-phase, $\mathrm{pg} \mathrm{m}^{-3}$ ) at land-based and oceanic sites.

\begin{tabular}{|c|c|c|c|c|c|c|c|}
\hline \multirow[t]{2}{*}{ Sites } & \multirow[t]{2}{*}{ Sampling Year } & \multirow[t]{2}{*}{ Sampling technique } & \multicolumn{2}{|l|}{ FTOHs } & \multicolumn{2}{|l|}{ FOSE/As } & \multirow[t]{2}{*}{ Reference } \\
\hline & & & Average & Range & Average & Range & \\
\hline North Sea & 2009 & HV-AAS ${ }^{\mathrm{a}}$ & 77.0 & $34.4-114$ & 13.1 & $5.4-40.9$ & Xie et al., 2013 \\
\hline Japan Sea & 2010 & HV-AAS & 178 & $70.9-363$ & 9.0 & $3.7-19.5$ & Cai et al., 2012 \\
\hline Station Nord, Greenland & $2008-2013$ & HV-AAS & 9.34 & $1.97-22.6^{\mathrm{d}}$ & 1.88 & $0.31-5.46$ & Bossi et al., 2016 \\
\hline Atlantic Ocean & 2010-2011 & HV-AAS & 19.9 & $2.06-62.6$ & 0.88 & $0.15-2.72$ & Wang et al., 2015b \\
\hline Ny-Ålesund, Norway & $2011-2012$ & HV-AAS & 14 & $5.6-34$ & 0.8 & $0.2-2.2$ & Xie et al., 2015 \\
\hline Bohai Sea & 2012 & HV-AAS & 104 & $78.5-163$ & 1.94 & $0.49-4.53$ & Zhao et al., 2017 \\
\hline North Yellow Sea & 2012 & HV-AAS & 184 & $155-214$ & 3.09 & $2.38-3.98$ & \\
\hline South Yellow Sea & 2012 & HV-AAS & 288 & $185-521$ & 4.44 & $0.63-9.75$ & \\
\hline South China Sea & 2013 & HV-AAS & 53.0 & $17.8-106$ & 1.2 & $0.1-3.6$ & Lai et al., 2016 \\
\hline China & 2009 & $\mathrm{SIP}^{\mathrm{b}}$ & 58.5 & $7.91-229$ & 14.8 & $6.45-23.7$ & Li et al., 2011,c \\
\hline India & & & 28.0 & $11.7-65.0$ & 51.1 & $5.46-434$ & \\
\hline Japan & & & 78.5 & $19.4-299$ & 17.4 & $3.66-76.5$ & \\
\hline Toronto, Canada & 2010 & HV-AAS & 81 & $39-146$ & 2.22 & BDL-3.68 & Ahrens et al., 2012 \\
\hline Zürich, Switzerland & 2010 & HV-AAS & 868 & $249-1.52 \times 10^{3}$ & 66.1 & $39.0-112$ & Müller et al., 2012 \\
\hline Büsum, Germany & $2011-2012$ & HV-AAS & 37 & $7.3-146$ & 5.0 & $1.2-18$ & Wang et al., 2014d \\
\hline Mountain top, Jixian & 2013 & SIP & 62.7 & - & 0.32 & - & Yao et al., 2016a,b \\
\hline Tianjin, China & & & 117 & $93.6-131$ & 0.72 & $0.43-0.96$ & \\
\hline Tianjin, China(S) ${ }^{e}$ & 2014 & HV-AAS & 151 & $60.2-2.51 \times 10^{3}$ & 69.6 & $3.43-323$ & This study $^{\mathrm{d}}$ \\
\hline Tianjin, China $(W)^{e}$ & & & 248 & $87.8-4.51 \times 10^{3}$ & 215 & $51.3-2.02 \times 10^{3}$ & \\
\hline Weifang, China(S) & & & 78.3 & $26.4-238$ & 0.11 & $0.05-0.23$ & \\
\hline Weifang, China(W) & & & 153 & $76.1-938$ & 0.57 & BDL-12.7 & \\
\hline $\mathrm{NHI}^{\mathrm{f}}$, China $(\mathrm{S})$ & & & 22.0 & $3.23-98.0$ & 0.07 & BDL-0.09 & \\
\hline NHI, China (W) & & & 48.6 & $19.4-183$ & 0.16 & BDL-0.45 & \\
\hline
\end{tabular}

a HV-AAS means high-volume active air sampler.

b SIP means sorbent-impregnated passive air sampler.

c The values were reconverted with a sampling rate of $4 \mathrm{~m}^{3}$ /day as recommended by Ahrens et al. (2013).

d Median values were used for comparison.

e $\mathrm{S}$ and $\mathrm{W}$ in the brackets represent summer and winter, respectively.

${ }^{f} \mathrm{NHI}$ represents North Huangcheng Island.

frequencies to the south of the island, indicating the air mass was mainly from Shandong province, where the WF site is located. In winter, the highest levels were detected at 373-502 $\mathrm{pg} \mathrm{m}^{-3}$ and FTOHs were dominant analogues (41\%). The frequencies of air mass trajectories covered mainly the west of the island apart from the southern Shandong province. These results demonstrate that the metropolitan area of TJ to the west of the island is a major source of FTOHs in the atmosphere. High levels of long-chain PFCAs (mainly PFOA) in the atmosphere to the south are probably associated with industrial activities. It is also noteworthy that the high air levels of FTOHs detected at NHI in winter were accompanied by high TSP levels of 78.5-162 $\mathrm{g} \mathrm{m} \mathrm{m}^{-3}$, while high levels of long-chain PFCAs in summer were associated with only moderate TSP levels of 23.2-76.6 $\mu \mathrm{g} \mathrm{m}^{-3}$. This suggests the atmospheric transport of FTOHs may be associated with particulate matter.

\subsection{Partitioning between gas and particle phases}

The particle-phase fractions $\left(f_{\mathrm{p}}\right)$ of $8: 2$ and 10:2 FTOHs at all the three sampling sites were calculated and plotted against their Log $K_{\mathrm{OA}}$ values (Fig. 2) that were calculated with sampling temperatures (Tables S2-7) (Thuens et al., 2008). The $f_{\mathrm{p}}$ values of $8: 2$ and 10:2 FTOHs were generally low (median $2.5 \%$ and 3.0\%, respectively) in summer and no significant correlation was observed with their $\log K_{\mathrm{OA}}$ values $(p>0.05)$. In winter, together with their elevated concentrations (Fig. 1A), a significant increase of $f_{\mathrm{p}}$ values $(p<0.01$ ) was observed for both 8:2 and 10:2 FTOHs (median $24.2 \%$ and $65.8 \%$, respectively) and the $f_{\mathrm{p}}$ values of $10: 2 \mathrm{FTOH}$ were significantly higher than those of 8:2 FTOH $(p<0.01)$. Further, $f_{\mathrm{p}}$ values of FTOHs were significantly correlated with their $\log K_{\mathrm{OA}}$ values in winter (Pearson's $r=0.691, p<0.01$ ). From summer to winter, the sampling temperature dropped from $25.0 \pm 2.1^{\circ} \mathrm{C}$ to $1.2 \pm 1.5^{\circ} \mathrm{C}$, which in theory increases the $\log K_{\mathrm{OA}}$ of FTOHs values by approximately $0.8 \log$-unit (Dreyer et al., 2009a). Similarly, the $f_{\mathrm{p}}$

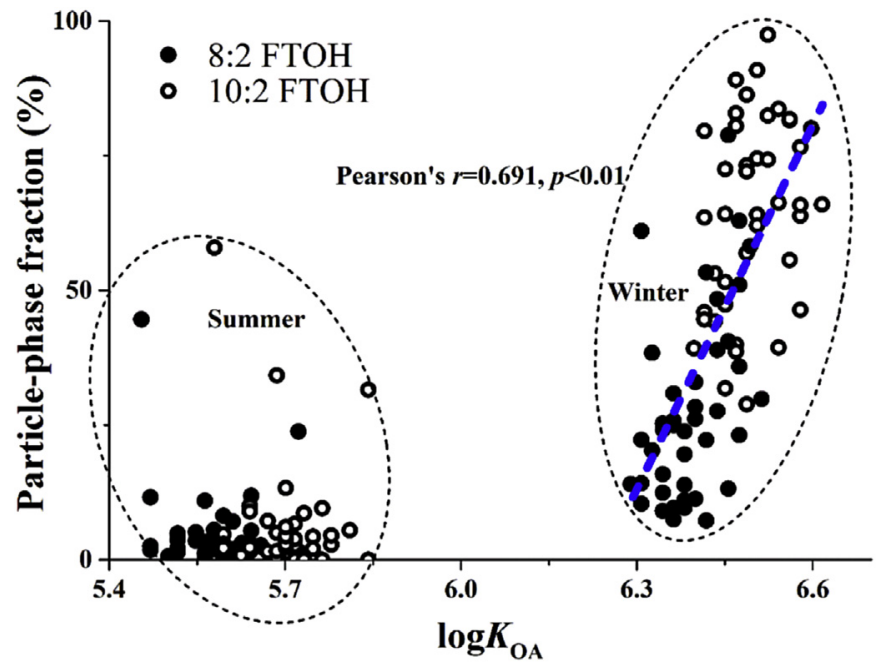

Fig. 2. Distribution and correlation between particle-phase fractions $\left(f_{\mathrm{p}}\right)$ of FTOHs and their $\log K_{\mathrm{OA}}$ values. Hollow marks are for the fractions in the summer and solid marks for the winter. The average levels of TSP were 60,192 , and $208 \mu \mathrm{g} \mathrm{m}^{-3}$, for NHI, TJ, and $W F$, respectively. No statistically significant difference was observed between the two seasons.

values of $N$-EtFOSA at TJ were significantly higher in winter than in summer (95.9\% vs. $13.9 \%$ ) and generally higher than those FTOHs due to its relatively high $\log K_{\mathrm{OA}}$ values (Dreyer et al., 2009a). These results suggest that temperature is an important factor determining the partitioning of neutral PFASs to particulate matter.

PFAAs may be preferentially adsorbed on GFFs (Arp and Goss, 2008), thus, their phase-distribution analysis may not be applicable based on data from HV-AAS (Johansson et al., 2017). Nevertheless, in the cases where air levels of PFOA or PFOS exceeded 

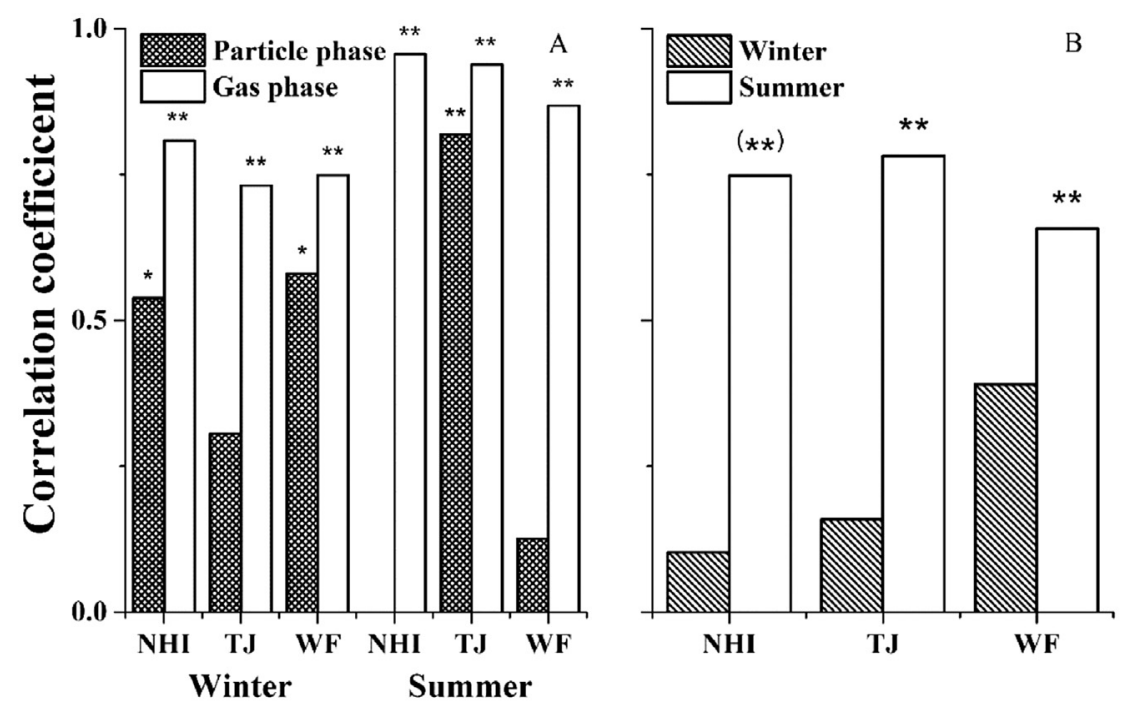

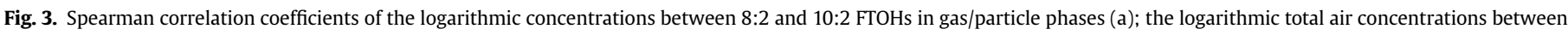

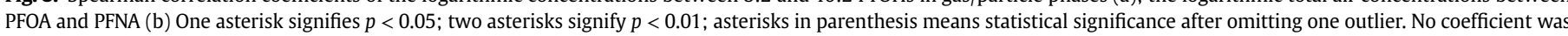
available for FTOHs in the particle phase at $\mathrm{NHI}$ in the summer due to the low detection frequency of 10:2 FTOH.

$1000 \mathrm{pg} \mathrm{m}^{-3}$, over $90 \%$ of these PFAAs were trapped on GFFs. In contrast, at lower levels $\left(<100 \mathrm{pg} \mathrm{m}^{-3}\right)$, a wide-range contribution (up to $80 \%$ ) of PFAAs from air columns was found. The pattern was also observed for the NHI site itself. Therefore, even taking the preferential adsorption on GFFs into account, these results still indicate that high air levels of ionic PFASs are typically associated with particulate matter, which can be an important carrier for their direct atmospheric transport.

\subsection{Correlation analysis}

As shown in Fig. 3A, Spearman correlation analysis was conducted on the concentrations of 8:2 and 10:2 FTOHs in the gas and particle phases, respectively. In the gas phase, 8:2 and 10:2 FTOHs were all strongly correlated with coefficients slightly higher in summer $(0.868-0.956, p<0.01)$ than those in winter $(0.731-0.808$, $p<0.01)$. In the particle phase, a consistent drop of correlativity was observed for each group, especially in the winter when $f_{\mathrm{p}}$ values were high. No significant correlation was observed at TJ while the coefficients dropped to 0.538 and 0.580 at NHI and WF, respectively $(p<0.05)$. The reduction in correlativity suggests heterogeneous processes rather than partitioning may lead to an asynchronous change in concentrations of 8:2 and 10:2 FTOHs in the particle phase.

PFOA and PFNA are major PFCA products from gas-phase degradation of 8:2 FTOH in the atmosphere (Ellis et al., 2004). As shown in Fig. 3B, the Spearman correlation analysis was conducted on the total air concentrations of PFOA and PFNA. In summer, the correlativity was strongly significant at $\mathrm{NHI}$ and $\mathrm{TJ}(0.748$ and 0.782 , $p<0.01)$, and comparatively weaker at WF $(0.657, p<0.01)$. Together with relatively lower levels of FTOHs in summer, these results indicate that PFOA and PFNA are yielded more efficiently from the atmospheric degradation of 8:2 FTOH and its derivatives when the temperature is high. PFOA might also have been released directly from industrial sources at WF, which compromised the correlativity. In winter, the correlativity was no longer statistically significant and dropped consistently to $0.103-0.391(p>0.05)$ at all three sites. These results may be ascribed to remarkably high $f_{\mathrm{p}}$ values of FTOHs. Heterogeneous processes may influence the fate of FTOHs and the yield of PFCAs in the atmosphere. It has been suggested that FTOHs undergo heterogeneous degradation when they come into contact with components of catalytic activity in atmospheric particulate matter (Styler et al., 2013). The process was considered to be much faster than gas-phase reactions and FTUCAs were major intermediates before being transformed into PFCAs. Fluorotelomer saturated carboxylic acid were proposed as a major product in gas-phase reactions; they can be transformed directly into odd-chain PFCAs and FTUCAs in a heterogeneous pathway as well (Styler et al., 2013). In the present study, the median levels of FTUCAs were $1.61,2.79$, and $2.70 \mathrm{pg} \mathrm{m}^{-3}$ at NHI, TJ, and $\mathrm{WF}$, respectively. Comparable levels of 8:2 FTUCA were also determined in the atmospheric particle phase at Zürich (Müller et al., 2012). Overall, statistically significant correlations $(p<0.01)$ of 8:2 FTUCA with PFOA and PFNA were found in both summer and winter with a moderate correlativity of $0.437-0.565$ using log-transformed air concentrations. This suggests heterogeneous degradation of atmospheric FTOHs and their derivatives may contribute to their loss mechanisms in both seasons.

\section{Conclusions}

This is the first comprehensive study that has reported air concentrations of a suite of PFASs (neutral and ionic PFASs) in both the gas and particle phases at two distinct sampling sites TJ and WF along the coast and a background oceanic site NHI of the Bohai Sea in China. DiPAPs were detected only in the particle phase with a total concentration range of $0.02-6.72 \mathrm{pg} \mathrm{m}^{-3}$ and $6: 2$ diPAP was dominant. PFASs were frequently detected with a total level of 80.1-206 $\mathrm{pg} \mathrm{m}^{-3}$ at NHI, which is an isolated oceanic island. Air mass backward-trajectory analysis of $\mathrm{NHI}$ data suggests that the metropolitan area of $\mathrm{TJ}$ is a source of neutral PFASs while air mass from Shandong province may receive a direct release of PFOA, possibly due to industrial activities. The strong correlativity of PFOA and PFNA and comparatively lower levels of FTOHs in summer suggest a more active gas-phase degradation of FTOHs. In winter, the $f_{\mathrm{p}}$ values of FTOHs were significantly higher than in summer and they were significantly correlated with their $\log K_{\mathrm{OA}}$ values, suggesting a temperature-dependent partitioning of FTOHs. A significant drop in correlativity between total air concentrations of PFOA and PFNA occurred in winter, suggesting an increasing 
complexity in their sources. 8:2 FTUCA was moderately correlated with PFOA and PFNA in both seasons, which were all statistically significant $(p<0.01)$. This further indicates that heterogeneous degradation may be involved in the loss mechanisms for atmospheric FTOHs in both seasons. Therefore, particulate matter played an important role in atmospheric transport and in determining the fate of PFASs, especially from a source region with TSP levels up to $200 \mu \mathrm{g} \mathrm{m}^{-3}$. Further, it is necessary to account for ionic PFASs in both QFFs and air columns if HV-AAS is used as a sampling technique in order to reflect their true air levels in total; thus, it will be possible to evaluate more accurately their LRAT potential and possible influences on non-source regions.

\section{Acknowledgments}

This work was financially supported by the Key Research Programs of the Chinese Academy of Sciences (No. KZZD-EW-14; XDA11020402), Natural Science Foundation of China (No, 41573097; 41225014), Ministry of Education of China(No, 20130031110027; IRT13024), and the CAS Visiting Professorship for Senior International Scientists (No, 2013T2Z0032).

\section{Appendix A. Supplementary data}

Supplementary data related to this article can be found at http:// dx.doi.org/10.1016/j.atmosenv.2017.08.023.

\section{References}

3M, 2000. Phase-out plan for POSF-based products, 2000. as document EPA-HQOPPT-2002-0043-0009. www.regulations.gov.

Ahrens, L., Harner, T., Shoeib, M., Lane, D.A., Murphy, J.G., 2012. Improved characterization of gas-particle partitioning for per- and polyfluoroalkyl substances in the atmosphere using annular diffusion denuder samplers. Environ. Sci. Technol. 46, 7199-7206.

Ahrens, L., Harner, T., Shoeib, M., Koblizkova, M., Reiner, E.J., 2013. Characterization of two passive air samplers for per- and polyfluoroalkyl substances. Environ. Sci. Technol. 47, 14024-14033.

Arp, H.P.H., Goss, K.U., 2008. Irreversible sorption of trace concentrations of perfluorocarboxylic acids to fiber filters used for air sampling. Atmos. Environ. 42 6869-6872.

Arp, H.P.H., Niederer, C., Goss, K.-U., 2006. Predicting the partitioning behavior of various highly fluorinated compounds. Environ. Sci. Technol. 40, 7298-7304.

Barber, J.L., Berger, U., Chaemfa, C., Huber, S., Jahnke, A., Temme, C., Jones, K.C., 2007 Analysis of per- and polyfluorinated alkyl substances in air samples from Northwest Europe. J. Environ. Monit. 9, 530-541.

Benskin, J.P., Phillips, V., St Louis, V.L., Martin, J.W., 2011. Source elucidation of perfluorinated carboxylic acids in remote alpine lake sediment cores. Environ. Sci. Technol. 45, 7188-7194.

Bossi, R., Vorkamp, K., Skov, H., 2016. Concentrations of organochlorine pesticides polybrominated diphenyl ethers and perfluorinated compounds in the atmosphere of North Greenland. Environ. Pollut. 217, 4-10.

Buck, R.C., Franklin, J., Berger, U., Conder, J.M., Cousins, I.T., de Voogt, P., Jensen, A.A., Kannan, K., Mabury, S.A., van Leeuwen, S.P., 2011. Perfluoroalkyl and polyfluoroalkyl substances in the environment: terminology, classification, and origins. Integr. Environ. Assess. Manag. 7, 513-541.

Cai, M., Xie, Z., Möller, A., Yin, Z., Huang, P., Cai, M., Yang, H., Sturm, R., He, J., Ebinghaus, R., 2012. Polyfluorinated compounds in the atmosphere along a cruise pathway from the Japan Sea to the Arctic Ocean. Chemosphere 87, 989-997.

Casal, P., Zhang, Y., Martin, J.W., Pizarro, M., Jimenez, B., Dachs, J., 2017. The role of snow deposition of perfluoroalkylated substances at coastal Livingston Island (Maritime Antarctica). Environ. Sci. Technol. 51, 8460-8470.

D'Eon, J.C., Hurley, M.D., Wallington, T.J., Mabury, S.A., 2006. Atmospheric chemistry of N-methyl perfluorobutane sulfonamidoethanol, C4F9SO2N(CH3) $\mathrm{CH} 2 \mathrm{CH} 2 \mathrm{OH}$ Kinetics and mechanism of reaction with OH. Environ. Sci. Technol. 40 1862-1868.

De Silva, A.O., Allard, C.N., Spencer, C., Webster, G.M., Shoeib, M., 2012. Phosphoruscontaining fluorinated organics: polyfluoroalkyl phosphoric acid diesters (diPAPs), perfluorophosphonates (PFPAs), and perfluorophosphinates (PFPIAs) in residential indoor dust. Environ. Sci. Technol. 46, 12575-12582.

Dreyer, A., Ebinghaus, R., 2009. Polyfluorinated compounds in ambient air from ship- and land-based measurements in northern Germany. Atmos. Environ. 43 1527-1535.

Dreyer, A., Langer, V., Ebinghaus, R., 2009a. Determination of octanol-air partition coefficients (KOA) of fluorotelomer acrylates, perfluoroalkyl sulfonamides, and perfluoroalkylsulfonamido ethanols. J. Chem. Eng. Data 54, 3022-3025.

Dreyer, A., Weinberg, I., Temme, C., Ebinghaus, R., 2009b. Polyfluorinated compounds in the atmosphere of the atlantic and southern oceans: evidence for a global distribution. Environ. Sci. Technol. 43, 6507-6514.

Dreyer, A., Kirchgeorg, T., Weinberg, I., Matthias, V., 2014. Particle-size distribution of airborne poly- and perfluorinated alkyl substances. Chemosphere 129, $142-149$.

D’eon, J.C., Crozier, P.W., Furdui, V.I., Reiner, E.J., Libelo, E.L., Mabury, S.A., 2009. Observation of a commercial fluorinated material, the polyfluoroalkyl phosphoric acid diesters, in human sera, wastewater treatment plant sludge, and paper fibers. Environ. Sci. Technol. 43, 4589-4594.

Ellis, D.A., Martin, J.W., Mabury, S.A., Hurley, M.D., Sulbaek Andersen, M.P., Wallington, T.J., 2003. Atmospheric lifetime of fluorotelomer alcohols. Environ. Sci. Technol. 37, 3816-3820.

Ellis, D.A., Martin, J.W., De Silva, A.O., Mabury, S.A., Hurley, M.D., Andersen, M.P.S., Wallington, T.J., 2004. Degradation of fluorotelomer alcohols: a likely atmospheric source of perfluorinated carboxylic acids. Environ. Sci. Technol. 38, 3316-3321.

Gao, Y., Fu, J.J., Cao, H.M., Wang, Y.W., Zhang, A.Q., Liang, Y., Wang, T., Zhao, C.Y., Jiang, G.B., 2015. Differential accumulation and elimination behavior of perfluoroalkyl acid isomers in occupational workers in a manufactory in China. Environ. Sci. Technol. 49, 6953-6962.

Gewurtz, S.B., Backus, S.M., De Silva, A.O., Ahrens, L., Armellin, A., Evans, M., Fraser, S., Gledhill, M., Guerra, P., Harner, T., Helm, P.A., Hung, H., Khera, N., Kim, M.G., King, M., Lee, S.C., Letcher, R.J., Martin, P., Marvin, C., McGoldrick, D.J., Myers, A.L., Pelletier, M., Pomeroy, J., Reiner, E.J., Rondeau, M., Sauve, M.C., Sekela, M., Shoeib, M., Smith, D.W., Smyth, S.A., Struger, J., Spry, D., Syrgiannis, J., Waltho, J., 2013. Perfluoroalkyl acids in the Canadian environment: multimedia assessment of current status and trends. Environ. Int. 59, 183-200.

Heydebreck, F., Tang, J.H., Xie, Z.Y., Ebinghaus, R., 2015. Alternative and legacy perfluoroalkyl substances: differences between european and Chinese river/ estuary systems. Environ. Sci. Technol. 49, 8386-8395.

Johansson, J.H., Berger, U., Cousins, I.T., 2017. Can the use of deactivated glass fibre filters eliminate sorption artefacts associated with active air sampling of perfluorooctanoic acid? Environ. Pollut. 224, 779-786.

Kissa, E., 2001. Fluorinated Surfactants and Repellents/Erik Kissa, Second ed. Dekker, cop. 2001, New York. rev, and expanded.

Kwok, K.Y., Taniyasu, S., Yeung, L.W.Y., Murphy, M.B., Lam, P.K.S., Horii, Y., Kannan, K., Petrick, G., Sinha, R.K., Yamashita, N., 2010. Flux of perfluorinated chemicals through wet deposition in Japan, the United States, and several other countries, Environ. Sci. Technol. 44, 7043-7049.

Kwok, K.Y., Wang, X.H., Ya, M., Li, Y., Zhang, X.H., Yamashita, N., Lam, J.C., Lam, P.K., 2015. Occurrence and distribution of conventional and new classes of per- and polyfluoroalkyl substances (PFASs) in the South China Sea. J. Hazard. Mater. 285, 389-397.

Lai, S.C., Song, J.W., Song, T.L., Huang, Z.J., Zhang, Y.Y., Zhao, Y., Liu, G.C., Zheng, J.Y., Mi, W.Y., Tang, J.H., Zou, S.C., Ebinghaus, R., Xie, Z.Y., 2016. Neutral polyfluoroalkyl substances in the atmosphere over the northern South China Sea. Environ. Pollut. 214, 449-455.

Lam, J.C., Lyu, J., Kwok, K.Y., Lam, P.K., 2016. Perfluoroalkyl substances (PFASs) in marine mammals from the South China Sea and their temporal changes 20022014: concern for alternatives of PFOS? Environ. Sci. Technol. 50, 6728-6736.

Lau, C., Anitole, K., Hodes, C., Lai, D., Pfahles-Hutchens, A., Seed, J., 2007. Perfluoroalkyl acids: a review of monitoring and toxicological findings. Toxicol. Sci. 99, 366-394.

Lee, H., Mabury, S.A., 2011. A pilot survey of legacy and current commercial fluorinated chemicals in human sera from United States donors in 2009. Environ. Sci. Technol. 45, 8067-8074.

Li, Y., Demerjian, K.L., Williams, L.R., Worsnop, D.R., Kolb, C.E., Davidovits, P., 2006. Heterogeneous uptake of 8:2 fluorotelomer alcohol on liquid water and 1octanol droplets. J. Phys. Chem. - Part A 110, 6814-6820.

Li, J., Del Vento, S., Schuster, J., Zhang, G., Chakraborty, P., Kobara, Y., Jones, K.C., 2011. Perfluorinated compounds in the Asian atmosphere. Environ. Sci. Technol. 45, $7241-7248$.

Liu, B.L., Zhang, H., Yao, D., Li, J.Y., Xie, L.W., Wang, X.X., Wang, Y.P., Liu, G.Q., Yang, B. 2015. Perfluorinated compounds (PFCs) in the atmosphere of Shenzhen, China: spatial distribution, sources and health risk assessment. Chemosphere 138, $511-518$.

Loi, E.I., Yeung, L.W., Mabury, S.A., Lam, P.K., 2013. Detections of commercial fluorosurfactants in Hong Kong marine environment and human blood: a pilot study. Environ. Sci. Technol. 47, 4677-4685.

Müller, C.E., Gerecke, A.C., Bogdal, C., Wang, Z., Scheringer, M., Hungerbuhler, K. 2012. Atmospheric fate of poly- and perfluorinated alkyl substances (PFASs): I. Day-night patterns of air concentrations in summer in Zürich. Switz. Environ. Pollut. 169, 196-203.

Piekarz, A.M., Primbs, T., Field, J.A., Barofsky, D.F., Simonich, S., 2007. Semivolatile fluorinated organic compounds in Asian and western U.S air masses. Environ. Sci. Technol. 41, 8248-8255.

Shoeib, M., Harner, T., Vlahos, P., 2006. Perfluorinated chemicals in the Arctic atmosphere. Environ. Sci. Technol. 40, 7577-7583.

Stock, N.L., Furdui, V.I., Muir, D.C.G., Mabury, S.A., 2007. Perfluoroalkyl contaminants in the canadian Arctic: evidence of atmospheric transport and local contamination. Environ. Sci. Technol. 41, 3529-3536.

Styler, S.A., Myers, A.L., Donaldson, D.J., 2013. Heterogeneous photooxidation of fluorotelomer alcohols: a new source of aerosol-phase perfluorinated 
carboxylic acids. Environ. Sci. Technol. 47, 6358-6367.

Thuens, S., Dreyer, A., Sturm, R., Temme, C., Ebinghaus, R., 2008. Determination of the octanol-air partition coefficients (KOA) of fluorotelomer alcohols. J. Chem. Eng. Data 53, 223-227.

US-EPA, 2010. PFOA stewardship program description. http://www.epa.gov/oppt/ pfoa/pubs/stewardship/pfoastewardshipbasics.html.

Vierke, L., Berger, U., Cousins, I.T., 2013. Estimation of the acid dissociation constant of perfluoroalkyl carboxylic acids through an experimental investigation of their water-to-air transport. Environ. Sci. Technol. 47, 11032-11039.

Wang, Z., MacLeod, M., Cousins, I.T., Scheringer, M., Hungerbühler, K., 2013. Using COSMOtherm to predict physicochemical properties of poly- and perfluorinated alkyl substances (PFASs). Environ. Chem. 8, 389-398.

Wang, P., Lu, Y., Wang, T., Fu, Y., Zhu, Z., Liu, S., Xie, S., Xiao, Y., Giesy, J.P., 2014a. Occurrence and transport of 17 perfluoroalkyl acids in 12 coastal rivers in south Bohai coastal region of China with concentrated fluoropolymer facilities. Environ. Pollut. 190, 115-122.

Wang, X., Halsall, C., Codling, G., Xie, Z., Xu, B., Zhao, Z., Xue, Y., Ebinghaus, R., Jones, K.C., 2014b. Accumulation of perfluoroalkyl compounds in Tibetan mountain snow: temporal patterns from 1980 to 2010. Environ. Sci. Technol. 48, $173-181$.

Wang, Z., Cousins, I.T., Scheringer, M., Buck, R.C., Hungerbuhler, K., 2014c. Global emission inventories for C4-C14 perfluoroalkyl carboxylic acid (PFCA) homologues from 1951 to 2030, Part I: production and emissions from quantifiable sources. Environ. Int. 70, 62-75.

Wang, Z., Xie, Z., Möller, A., Mi, W., Wolschke, H., Ebinghaus, R., 2014d. Atmospheric concentrations and gas/particle partitioning of neutral poly- and perfluoroalkyl substances in northern German coast. Atmos. Environ. 95, 207-213.

Wang, Z., Xie, Z., Möller, A., Mi, W., Wolschke, H., Ebinghaus, R., 2015a. Estimating dry deposition and gas/particle partition coefficients of neutral poly-/perfluoroalkyl substances in northern German coast. Environ. Pollut. 202, 120-125.

Wang, Z., Xie, Z.Y., Mi, W.Y., Moller, A., Wolschke, H., Ebinghaus, R., 2015b. Neutral poly/per-fluoroalkyl substances in air from the Atlantic to the Southern Ocean and in Antarctic snow. Environ. Sci. Technol. 49, 7770-7775.

Wang, P., Lu, Y.L., Wang, T.Y., Meng, J., Li, Q.F., Zhu, Z.Y., Sun, Y.J., Wang, R.S., Giesy, J.P., 2016. Shifts in production of perfluoroalkyl acids affect emissions and concentrations in the environment of the Xiaoqing River Basin, China. J. Hazard. Mater. 307, 55-63.

Xie, Z., Zhao, Z., Moller, A., Wolschke, H., Ahrens, L., Sturm, R., Ebinghaus, R., 2013. Neutral poly- and perfluoroalkyl substances in air and seawater of the North Sea. Environ. Sci. Pollut. Res. Int. 20, 7988-8000.

Xie, Z., Wang, Z., Mi, W., Möller, A., Wolschke, H., Ebinghaus, R., 2015. Neutral polyperfluoroalkyl substances in air and snow from the Arctic. Sci. Reports-Uk 5, 8912.

Yao, Y., Zhu, H., Li, B., Hu, H., Zhang, T., Yamazaki, E., Taniyasu, S., Yamashita, N. Sun, H., 2014. Distribution and primary source analysis of per- and polyfluoroalkyl substances with different chain lengths in surface and groundwater in two cities, North China. Ecotoxicol. Environ. Saf. 108, 318-328.

Yao, Y., Chang, S., Sun, H., Gan, Z., Hu, H., Zhao, Y., Zhang, Y., 2016a. Neutral and ionic per- and polyfluoroalkyl substances (PFASs) in atmospheric and dry deposition samples over a source region (Tianjin, China). Environ. Pollut. 212, 449-456.

Yao, Y., Sun, H., Gan, Z., Hu, H., Zhao, Y., Chang, S., Zhou, Q., 2016b. Nationwide distribution of per- and polyfluoroalkyl substances in outdoor dust in mainland China from eastern to western areas. Environ. Sci. Technol. 50, 3676-3685.

Yeung, L.W., Robinson, S.J., Koschorreck, J., Mabury, S.A., 2013. Part I. A tempora study of PFCAs and their precursors in human plasma from two German cities 1982-2009. Environ. Sci. Technol. 47, 3865-3874.

Yuan, Q., Ma, G.C., Xu, T., Serge, B., Yu, H.Y., Chen, J.R., Lin, H.J., 2016. Developing QSPR model of gas/particle partition coefficients of neutral poly-/perfluoroalkyl substances. Atmos. Environ. 143, 270-277.

Zhao, Z., Xie, Z., Moller, A., Sturm, R., Tang, J., Zhang, G., Ebinghaus, R., 2012. Distribution and long-range transport of polyfluoroalkyl substances in the Arctic Atlantic Ocean and Antarctic coast. Environ. Pollut. 170, 71-77.

Zhao, L., Zhou, M., Zhang, T., Sun, H., 2013. Polyfluorinated and perfluorinated chemicals in precipitation and runoff from cities across eastern and central China. Archives Environ. Contam. Toxicol. 64, 198-207.

Zhao, Z., Tang, J., Mi, L., Tian, C., Zhong, G., Zhang, G., Wang, S., Li, Q., Ebinghaus, R. Xie, Z., Sun, H., 2017. Perfluoroalkyl and polyfluoroalkyl substances in the lower atmosphere and surface waters of the Chinese Bohai Sea, Yellow Sea, and Yangtze River estuary. Sci. Total Environ. 599-600, 114-123. 